\title{
BMJ Open Prevalence of xenobiotic substances in first-trimester blood samples from Danish pregnant women: a cross- sectional study
}

\author{
Sissel Kramer Aagaard, ${ }^{1,2}$ Agnete Larsen, ${ }^{2}$ Mette Findal Andreasen, ${ }^{3}$ \\ lana Lesnikova, ${ }^{4}$ Rasmus Telving, ${ }^{3}$ Anna Louise Vestergaard, ${ }^{1,2}$ Niels Tørring, ${ }^{5}$ \\ Niels Uldbjerg, ${ }^{6}$ Pinar Bor ${ }^{1}$
}

To cite: Aagaard SK, Larsen A, Andreasen MF, et al. Prevalence of xenobiotic substances in first-trimester blood samples from Danish pregnant women: a cross-sectional study. BMJ Open 2018;8:e018390. doi:10.1136/ bmjopen-2017-018390

- Prepublication history for this paper is available online. To view these files, please visit the journal online (http://dx.doi org/10.1136/bmjopen-2017018390).

Received 27 June 2017 Revised 29 August 2017 Accepted 28 September 2017

Check for updates

${ }^{1}$ Department of Obstetrics and Gynecology, Randers Regional Hospital, Randers, Denmark ${ }^{2}$ Department of Biomedicine, Aarhus University, Aarhus, Denmark

${ }^{3}$ Section for Forensic Chemistry, Department of Forensic Medicine, Aarhus University, Aarhus, Denmark

${ }^{4}$ Vidant Medical Center, Greenville, North Carolina, USA ${ }^{5}$ Department of Clinical Biochemistry, Aarhus University Hospital, Aarhus, Denmark ${ }^{6}$ Department of Obstetrics and Gynecology, Aarhus University Hospital, Aarhus, Denmark

Correspondence to Dr Pinar Bor; isipinbo@rm.dk

\section{ABSTRACT}

Objective The aim of this study was to investigate the prevalence of xenobiotic substances, such as caffeine, nicotine and illicit drugs (eg, cannabis and cocaine), in blood samples from first-trimester Danish pregnant women unaware of the screening.

Design A cross-sectional study examined 436 anonymised residual blood samples obtained during 2014 as part of the nationwide prenatal first-trimester screening programme. The samples were analysed by ultra performance liquid chromatography with high-resolution time-of-flight mass spectrometry.

Setting An antenatal clinic in a Danish city with 62000 inhabitants, where $>95 \%$ of pregnant women joined the screening programme.

Primary and secondary outcome measures The prevalence and patterns of caffeine, nicotine, medication and illicit drug intake during the first trimester of pregnancy. Results The prevalence of prescription and overthe-counter drug detection was $17.9 \%$, including acetaminophen (8.9\%) and antidepressants (3.0\%), of which citalopram $(0.9 \%)$ was the most frequent. The prevalence of illegal drugs, indicators of smoking (nicotine/ cotinine) and caffeine was $0.9 \%, 9.9 \%$, and $76.4 \%$, respectively. Only $17.4 \%$ of women had no substance identified in their sample.

Conclusions This study emphasises the need for further translational studies investigating lifestyle habits during pregnancy, as well as the underlying molecular mechanisms through which xenobiotic substances may affect placental function and fetal development.

\section{INTRODUCTION}

Since the thalidomide catastrophe of the 1960 s, ${ }^{1}$ in which a seemingly safe antiemetic drug caused major congenital malformations in children worldwide, focus on avoiding teratogenic exposures during pregnancy has increased. However, with the Developmental Origins of Health and Disease Hypothesis $(\mathrm{DOHaD}),{ }^{2}{ }^{3}$ the need for a deeper understanding of less-recognised threats to fetal health has become more apparent. According
Strengths and limitations of the study

- The pregnant women were unaware of the screening, eliminating information and recall bias as potential sources of error, as the blood samples analysed were anonymised surplus blood samples from the prenatal screening programme.

- Ultra performance liquid chromatography with high-resolution time-of-flight mass spectrometry is a broad targeting method that has been validated for the 225 most toxicologically relevant drugs and metabolites that also supplies patterns of coexposure, as all substances are detected at once.

- As the study was based on anonymous blood samples, we had no opportunity to follow-up the children prospectively.

- We only had a single blood sample from the first trimester and no samples from late pregnancy, which would have provided further information by confirming exposure patterns and/or identifying changes in exposure during pregnancy.

to the $\mathrm{DOHaD}$, early pregnancy constitutes a highly sensitive period during which environmental factors can affect fetal development. The intrauterine environment is thus believed to 'programme' the fetus and placenta through subtle molecular changes, that is, changes of the epigenome that alter gene regulation and affect disease risk later in life. ${ }^{2-4}$ Such epigenetic alterations have already been linked to the development of many chronic diseases, including type 2 diabetes $^{5}$ and cardiovascular illnesses. ${ }^{6}$ To unravel potential links between disease development later in life and epigenetic changes, a better understanding of the exposures currently affecting pregnant women is needed. In this respect, attention should be focused on all xenobiotic substances (substances not normally found in the human body, ranging from medications to nicotine 
or caffeine), which might constitute a potential health risk during pregnancy or later in the life of the child.

The use of prescription medications in the first trimester of pregnancy has increased $>60 \%$ over the past three decades. ${ }^{7}$ Previous international studies have found that up to $94 \%$ of all pregnant women take some form of medication at least once during their pregnancy, ${ }^{7-9}$ most frequently over-the-counter drugs $(66.9 \%)$, but also treatments for long-term or chronic disorders (as much as 17\% of women). ${ }^{8}$ Cultural differences in the use of medicines and other potential harmful exposures are evident. In the USA, it is estimated that $17 \%-25 \%$ of young women of fertile age are habitual smokers. ${ }^{10-12}$ However, recent data from the Danish Health Protection Agency found that only $12 \%$ of Danish pregnant women smoke daily. ${ }^{13}$ Many adverse effects of smoking are well known, ${ }^{14-17}$ but the patterns of co-exposure between smoking and other xenobiotics are not well-described, making it difficult to track harmful combinations and describe the mechanisms involved. Additionally, the prevalence of harmful exposures such as illicit drug use during pregnancy is relatively unknown in the Danish setting, despite the fact that numerous adverse pregnancy outcomes are related to drug abuse. $^{1218}$ The latest Danish population survey from 2013 found that $46 \%$ of young Danes under the age of 35 had experimented with cannabis and approximately $9 \%$ of them had at least once tried other illegal drugs in addition to cannabis, with cocaine and amphetamines being the most commonly reported..$^{19}$ An increasing use of certain forms of psychostimulants such as methylphenidate (eg, Ritalin) has also been reported among Danish pregnant women. ${ }^{20}$ Epidemiological studies have linked intrauterine exposure to attention-deficit/hyperactivity disorder (ADHD) medications (methylphenidate or atomoxetine) with lower Apgar scores at birth and an increased risk of miscarriage. ${ }^{21}$ This underscores the need for more knowledge of illicit drug use during pregnancy.

The majority of previous studies investigating the use of medication during pregnancy have been based on retrospective self-reporting or searching in national prescription registries, and may thus be affected by recall and selection bias. Hence, the aim of this study was to characterise the use of prescription-type medicine, over-the-counter medicine and psychoactive substances in the blood of first-trimester pregnant Danish women who were unaware of the screening. We aimed to investigate both the prevalence and pattern of xenobiotic substance use, such as medicines, caffeine, nicotine and illicit drugs (eg, cannabis and cocaine), in pregnant women. We also aimed to include the use of over-the-counter medications, which has not been otherwise described when using the national prescription registries.

\section{MATERIALS AND METHODS}

\section{Design and study group}

The study was designed as a cross-sectional study, in which the study population consisted of the pregnant women from the municipality of Randers, Denmark who had participated in the national prenatal screening programme between gestational week 8-13. As part of the screening programme, blood samples (for the double test) are always drawn and the unused portion of the samples is stored in a biobank at $-80^{\circ} \mathrm{C}^{22}$ for quality control purposes. All women with residual blood in the biobank were theoretically eligible to participate in the study. However, our inclusion criterion was that the original double test analysis must have occurred during the first 8 days of each month in 2014. Each woman contributed one sample. There were no specific exclusion criteria.

All blood samples were drawn either by family general practitioners or in outpatient settings connected to Randers Regional Hospital. Serum was isolated and samples were shipped to the Department of Clinical Biochemistry, Aarhus University Hospital, within 4 hours, recentrifuged and stored at $4^{\circ} \mathrm{C}$ until the double test analysis could be performed, 12-36 hours after sample collection. The unused portions of the samples were stored in the biobank at $-80^{\circ} \mathrm{C}^{22}$ until our analysis was performed in the spring of 2016.

Pregnant women who had participated in the prenatal screening programme and attended the first-trimester scan with risk assessment in 2014 were identified using a treatment code. Their blood samples were subsequently identified in the biobank through barcode numbers, anonymised and delivered for analysis. A total of 436 samples fitting the inclusion criterion were analysed in the present study. This corresponds to $23.5 \%$ of the pregnant women who underwent first trimester nuchal translucent scans at Randers Regional Hospital in 2014.

\section{Ethical aspects}

All data were handled and stored in a de-identified manner.

\section{Sample and data analysis}

Serum samples were thawed, and $300 \mu \mathrm{L}$ of each serum sample were transferred to an Eppendorf plate and analysed for the presence of substances using a forensic analytical method as described by Telving et al. ${ }^{23}$ Approximately 500 different substances comprising toxic compounds, illegal and legal drugs and several of their metabolites could be identified using protein precipitation followed by ultra performance liquid chromatography with high-resolution time-of-flight mass spectrometry (UPLCHR-TOFMS analysis) ${ }^{23} \mathrm{~A}$ list of the substances included in this method can be found in the supplementary section of the methods in the article by Telving et al. ${ }^{23}$ This method has been validated for the 225 most toxicologically relevant drugs and metabolites. The supplementary section ${ }^{23}$ also summarises the cut-off values for these substances in antemortem whole blood. The method cannot detect alcohol or all types of medications used by pregnant women, that is, only certain antiemetic drugs (eg, metoclopramide and ondansetron) and the most frequently 
used antihypertensive drugs (eg, amlodipine, furosemide, diltiazem and metoprolol). Furthermore, antibiotics and thyroid medications, such as levothyroxine, could not be assessed by the UPLC-HR-TOFMS analysis.

The presence of a substance and all related metabolites from each blood sample were counted as one exposure in a given sample, for example, nicotine and/or cotinine as indicators of smoking. In several cases, substances were identified solely based on the presence of their metabolites (eg, benzoylecgonine, a metabolite of cocaine).

The analysing laboratory is accredited by an external independent organisation, DANAK (Danish Accreditation), and participates in various screening and quantification proficiency tests. All results from the UPLC-HR-TOFMS analysis were evaluated by two experienced persons at the Section for Forensic Chemistry, as described by Telving et $_{\text {al. }}{ }^{23}$

\section{RESULTS}

We found the prevalence of xenobiotic substances (medications, caffeine, nicotine and illicit drugs) in first-trimester Danish pregnant women to be $82.6 \%$. Thus, only in $17.4 \%$ of the samples there was no trace of any exogenous substance detected. However, in $62 \%$ of samples, only one substance was identified, whereas $16.2 \%$ contained two substances and $3.6 \%$ of the samples contained evidence of three or more substances. Table 1 shows all the identified substances. As several of the women had traces of more than one substance, these women are counted more than once in table 1 .

\section{Over-the-counter and prescription medicine}

In $17.9 \%(\mathrm{n}=78)$ of the samples, we identified traces of medicine; a total of 27 different forms of medications were identified (see table 1 for details). The prevalence of over-the-counter medications (acetaminophen, ibuprofen, aspirin, analgesic bandages or antihistamines) was $11.9 \% \quad(n=52)$, and the prevalence of medication available only with a prescription in Denmark was 7.1\% $(\mathrm{n}=34)$. Samples with two or more drugs accounted for $2.1 \%(n=9)$ of all samples. A combination of over-thecounter and prescription medicine was found in $1.1 \%$ $(n=5)$ of our samples, and the combination of medication and caffeine was present in $13.5 \% \quad(n=59)$ of all samples. The frequencies of the different medications are given in table 1 , with analgesics $(11.7 \%)$ including acetaminophen $(9.4 \%)$ and codeine $(1.1 \%)$ being the most frequently used drug category.

Psychoactive medications (defined as antidepressants, antipsychotics, anxiolytics and methylphenidate) were identified in $3.7 \%$ of samples, with antidepressants $(3.0 \%)$ being the most frequent type and citalopram $(0.9 \%)$ being the drug most frequently used. Antipsychotic and anxiolytic drugs were identified in $0.7 \%$ and $0.2 \%$ of the samples, respectively. In addition, $0.5 \%$ of the samples contained antiepileptic drugs.
Antihistamines, antidiabetic drugs and the asthma medication salbutamol were also identified in $1.8 \%$, $1.8 \%$, and $0.2 \%$ of all samples, respectively.

\section{Illicit drugs}

We identified illicit drugs (including cannabis) and/or their metabolites in $0.9 \% \quad(n=4)$ of the serum samples (table 1). Cannabis was identified in all four illicit drug-positive samples $(0.9 \%)$. Moreover, amphetamine and benzoylecgonine (a cocaine metabolite) were also present in one of these samples.

\section{Caffeine and nicotine}

Caffeine was the most frequent substance used, identified in a total of $76.4 \%$ of the samples. Indicators of smoking (nicotine and cotinine, a metabolite of nicotine) were found in $9.9 \%$ of samples. Caffeine, nicotine and cotinine have psychoactive properties and, if considered as psychoactive substances alongside psychoactive medications and illicit drugs, as many as $79.4 \%$ of the pregnant women had used some form of psychoactive substance.

\section{DISCUSSION}

In this study, we found a high prevalence $(82.6 \%)$ of xenobiotics (medicine, caffeine, nicotine and illicit drugs) in blood samples from first-trimester Danish pregnant women. To the best of our knowledge, this is the first study investigating the prevalence and pattern of xenobiotic substance use in early pregnancy in women unaware of the screening. This study was strengthened by the inclusion of samples from Danish pregnant women who generally had a very high attendance rate $(95 \%)$ in prenatal screening programmes. ${ }^{24}$ Furthermore, this is the first study using this type of broad targeted substance screening on serum samples using UPLC-HR-TOFMS analysis, which can identify most relevant psychoactive medications, over-the-counter medications and illicit drugs found in the Danish population, although not the use of alcohol. ${ }^{23}$

Importantly, the cross-sectional study design only reflects the substance use within a short period of time, and it should be considered that habits may change during the pregnancy. Moreover, differences in the pharmacokinetics of various xenobiotics could also affect the likelihood of identifying a given substance. However, as the first trimester is the most sensitive and critical period in fetal development, it is critical to note that only $17.4 \%$ of pregnant women analysed in this study had no evidence of xenobiotic substances in their blood, indicating that early intervention is needed to prevent or regulate the use of medications during pregnancy. Due to ethical considerations, this analysis of samples from women unaware of the screening required anonymisation of the samples; hence, the present study is limited by the prevention of inclusion of perinatal outcomes in the analysis, which would very likely have been highly relevant in this context. 
Table 1 Substances identified

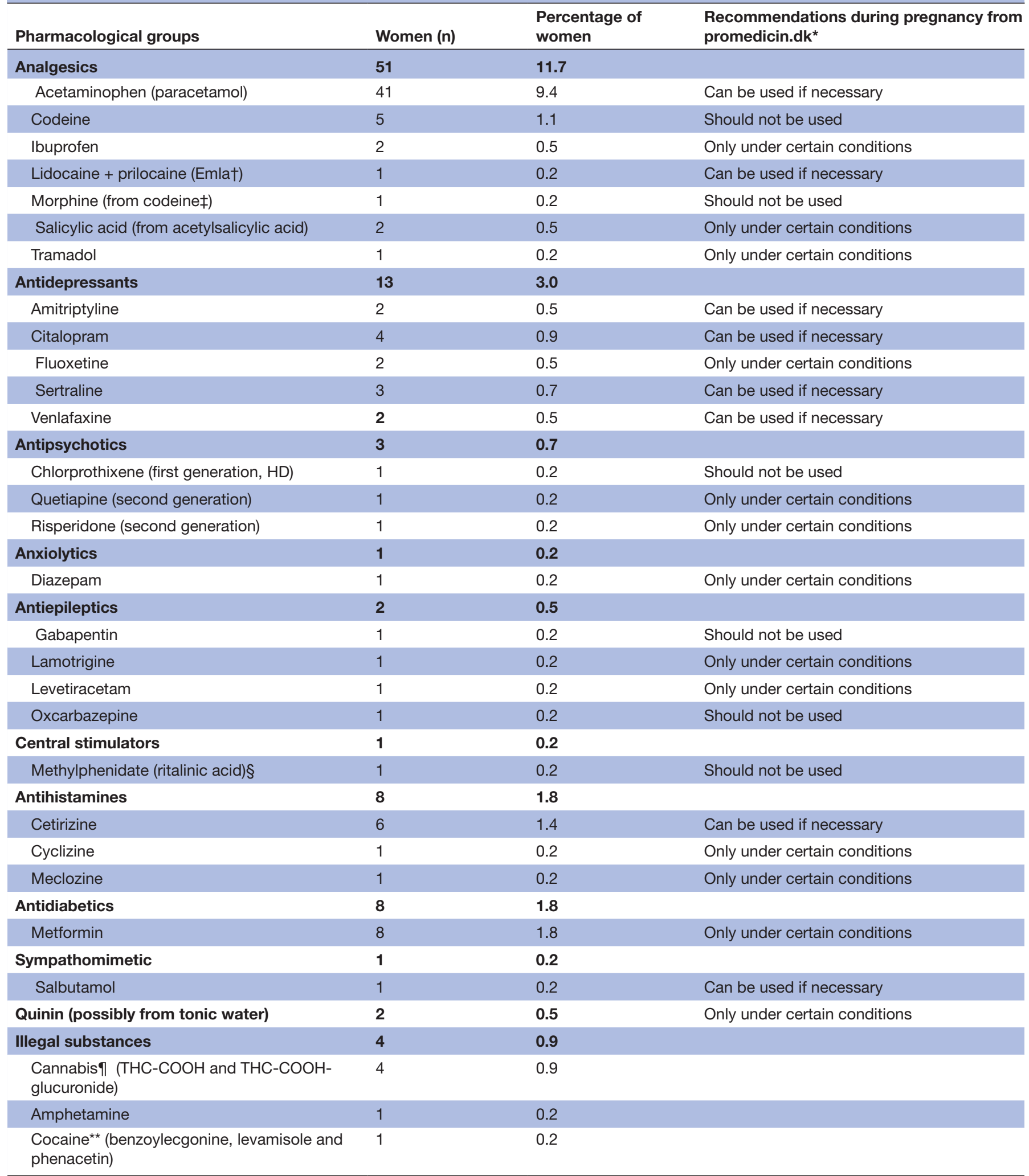

*Promedicin.dk is a Danish website developed by Danish Medicine Information for medical doctors and other healthcare personnel and contains detailed information on all marketed human medications. It is the most frequently used source of information on medication safety among Danish health professionals.

†Emla is a local anaesthetic containing lidocaine and prilocaine.

$\ddagger$ Morphine was found in a serum sample that also contained codeine, suggesting that the morphine could be a metabolite from codeine.

$\S$ Ritalinic acid is a metabolite of methylphenidate, indicating the use of methylphenidate.

IThe detected THC-COOH and THC-COOH glucuronide metabolites indicate the use of cannabis.

${ }^{\star \star}$ The detection of the metabolite benzoylecgonine and the 'cocaine cutting agents' levamisole and phenacetin indicates cocaine use. 
Pharmacological compounds available as over-thecounter drugs were the most frequent finding in this study. Acetaminophen was identified in a total of $9.4 \%$ of the samples. This finding raises concerns, as the use of acetaminophen during pregnancy might be associated with an increased risk of asthma, ${ }^{25}$ cryptorchidism, ${ }^{26} 27$ autism, hyperkinetic disorders and ADHD-like behaviour in children, ${ }^{28}{ }^{29}$ despite not being associated with major birth defects. ${ }^{30}$ Thus, the markedly high prevalence of acetaminophen use in this and previous studies ${ }^{27-30} \mathrm{em}$ phasises the need for further research concerning the more subtle effects of acetaminophen in the human placenta and early development.

The prevalence of ibuprofen and other over-the counter drugs of the non-steroidal anti-inflammatory drug family (NSAIDs) associated with adverse outcomes, such as increased risk of miscarriage $e^{3132}$ and congenital cardiac defects, ${ }^{33}$ was low $(0.5 \%)$. Similarly, the frequency of antihistamine use was only $1.8 \%$, which we consider surprisingly low as they are recommended for common conditions such as hyperemesis and allergies and have previously been reported to be widely used. ${ }^{34}$

In the present study, prescription drugs were found in $7.1 \%$ of the samples; other European studies have found a $79 \%$ prevalence of prescription drug use during pregnancy, with up to $48 \%$ of all pregnant women receiving a prescription in first trimester. ${ }^{735}$ This value likely reflects the design of this study, showing only a snapshot of the use of medicine among Danish pregnant women. The fact that certain types of drugs, such as antibiotics and antiemetic drugs, are not detected in the analytical method used $^{28}$ also contributes to the differences between these and previously reported results. The analytical method used includes substances that are relevant in forensic cases.

The most frequent group of prescription drugs identified in our study was antidepressants, with a frequency of $3 \%$. However, this was considerably lower than in a US study, which found that $6.6 \%$ of pregnant women used antidepressants. ${ }^{36}$ It remains unclear whether prenatal exposure to antidepressants and other psychoactive substances can impair brain development, cause postnatal neurobehavioural differences ${ }^{21} 37$ or increase the risk of miscarriage, ${ }^{38-40}$ major malformation, ${ }^{41-43}$ stillbirth and preterm birth. ${ }^{44}$

Among the prescription drugs identified, several are suspected of having adverse effects on fetal development and are thus not recommended for pregnant women (table 1). However, many of these drugs are also vital in the treatment of chronic diseases, highlighting the complexity of the safe use of medications in early pregnancy. Studies have shown that insufficient treatment of conditions such as depression, ${ }^{39}$ psychosis, ${ }^{45}$ epilepsy ${ }^{46}$ or inflammatory bowe ${ }^{47}$ disease during pregnancy can have negative effects on both the mother and child. Thus, when treating patients with psychiatric disorder or patients with other chronic diseases who are pregnant, it is important to consider the potential teratogenicity with the risk associated with the untreated diseases. ${ }^{39} 4547$ However, a deeper understanding of lifestyle patterns and the intake of non-prescription medications is needed to limit the risks to necessary medical treatments, just as emphasis should be placed on avoiding unnecessary multidrug treatments. The use of medications among the pregnant population calls for continued optimisation of obstetric guidelines. Reflecting the use of such guidelines, metformin was only identified in $1.8 \%$ of our samples, which is in accordance with the Danish guidelines advocating discontinuation during pregnancy when used for treatment of diabetes or PCOS.

The presence of illicit drugs $(0.9 \%)$ in our population appears relatively low compared with previous international studies, which have reported frequencies of up to 4.4\%. ${ }^{12} 18$ A Danish study from 1998 found that $2.1 \%$ of Danish pregnant women had used cannabis and $0.2 \%$ had used other illicit drugs within the last 3 months before recognition of pregnancy. ${ }^{48}$ Naturally, some form of 'healthy worker selection' or change of abuse pattern prior to the doctor's visit cannot be excluded, as cannabis is currently only approved for a severely limited number of conditions in Denmark and is presumably not used in the treatment of pregnant women. Thus, in other countries in which medical cannabis is legal, the prevalence rate among pregnant women may likely be higher.

Our findings show a high frequency of caffeine (76.4\%), even though only $40 \%$ of Danish pregnant women reported drinking coffee in previous studies. ${ }^{49} 50$ This discrepancy may be explained by the intake of caffeine-containing beverages and energy drinks. Regardless of the source, caffeine may affect the fetus as it crosses the placenta ${ }^{51}$ and can cause miscarriage, ${ }^{5253}$ fetal growth restriction ${ }^{545}$ and childhood leukaemia. ${ }^{56}$ Furthermore, animal studies indicate that caffeine exposure might potentiate the adverse effects of certain medications. ${ }^{5758}$

We found evidence of (habitual) cigarette smoking in nearly $10 \%$ of the samples, despite the fact that smoking in pregnancy is a well-known risk factor ${ }^{59}$ associated with an increased risk of placenta dysfunction ${ }^{15}$ and adverse birth outcomes, such as low birth weight and preterm birth. ${ }^{1460}$ As a previous report stated that $8 \%$ of pregnant women continue to smoke throughout pregnancy, ${ }^{61}$ this finding might reflect a continuous increase in smoking cessation during pregnancy. In recent years, prenatal exposure to cigarette smoke has also been associated with the development of diseases later in life, such as asthma and allergies ${ }^{62}$ metabolic diseases ${ }^{63}$ and certain forms of cancer. ${ }^{14}$ Moreover, prenatal exposure to cigarette smoke has been associated with behavioural deficiencies and neuropsychiatric disorders. ${ }^{16}{ }^{17}$ Many smokers reduce or quit smoking during pregnancy ${ }^{61}$; however, even shortterm exposure during the first trimester may still result in adverse effects on the fetus. In this respect, first-trimester exposure to maternal cigarette smoke has been shown to reduce the number of gonadal cells in both male and female human fetuses. ${ }^{64}$ Thus, our findings underline the 
importance of maintaining focus on early smoking cessation during pregnancy.

\section{CONCLUSION}

With the recognised limitation of being a one-timeonly analysis, this study provides unbiased knowledge regarding medication and substance abuse among Danish pregnant women seeking prenatal diagnostic advise at the end of the first trimester. The fact that almost one in five randomly selected Danish pregnant women displayed traces of medication in a single first-trimester blood sample in the present study underscores the critical need for early intervention to prevent or regulate the use of medication during pregnancy, as well as to address continuous exposure to caffeine and smoking in early pregnancy. The study emphasises the need for further studies on the mechanistic effects of xenobiotic exposures during pregnancy, as both legal and illegal drugs may be teratogenic or have adverse effects on placental function and ultimately have subtle effects on epigenetic alterations.

Acknowledgements The authors are grateful for financial support from the Faculty of Health at Aarhus University, supporting the research year of Sissel Kramer Aagaard; the support from the Research Department at Randers Regional Hospital, the Central Denmark Region; and the financial support from The Linex Foundation, Gross L F Foght's Foundation and Helga \& Peter Korning's Foundation.

Contributors Project design: NU, PB, IL, AL and MFA. Management of blood samples and data selection: NT. Blood analysis: SKA, MFA and RT. Data analysis: SKA under supervision of PB, IL, AL, MFA and NU. Drafting of the manuscript: SKA and ALV. Critical revision of the manuscript: PB, IL, AL, NU and MFA. All authors have commented on the manuscript.

Funding The study was supported by the Faculty of Health at Aarhus University, the Research Department at Randers Regional Hospital, The Linex Foundation, Gross L F Foght's Foundation and Helga \& Peter Korning's Foundation.

Competing interests None declared.

Patient consent Detail has been removed from this case description/these case descriptions to ensure anonymity. The editors and reviewers have seen the detailed information available and are satisfied that the information backs up the case the authors are making.

Ethics approval The study was approved by the Central Denmark Region Committee on Biomedical Research Ethics (1-10-72-22-16) and the Danish Data Protection Agency (1-16-02-255-16).

Provenance and peer review Not commissioned; externally peer reviewed.

Data sharing statement We have no unpublished data. All data are presented in the article.

Open Access This is an Open Access article distributed in accordance with the Creative Commons Attribution Non Commercial (CC BY-NC 4.0) license, which permits others to distribute, remix, adapt, build upon this work non-commercially, and license their derivative works on different terms, provided the original work is properly cited and the use is non-commercial. See: http://creativecommons.org/ licenses/by-nc/4.0/

(c) Article author(s) (or their employer(s) unless otherwise stated in the text of the article) 2018. All rights reserved. No commercial use is permitted unless otherwise expressly granted.

\section{REFERENCES}

1. Matthews SJ, McCoy C. Thalidomide: a review of approved and investigational uses. Clin Ther 2003;25:342-95.
2. Roseboom TJ, (Nils) Lambalk CB. The Fetal Origins Hypothesis. Twin Research and Human Genetics 2001;4:iii.

3. Roseboom TJ, van der Meulen JHP, Ravelli ACJ, et al. Effects of prenatal exposure to the Dutch famine on adult disease in later life: an overview. Mol Cell Endocrinol 2001;185:93-8.

4. Barker DJ, Thornburg KL. Placental programming of chronic diseases, cancer and lifespan: a review. Placenta 2013;34:841-5.

5. Olsson AH, Volkov P, Bacos K, et al. Genome-wide associations between genetic and epigenetic variation influence mRNA expression and insulin secretion in human pancreatic islets. PLoS Genet 2014;10:e1004735.

6. Barker DJ, Larsen G, Osmond C, et al. The placental origins of sudden cardiac death. Int J Epidemiol 2012;41:1394-9.

7. Mitchell AA, Gilboa SM, Werler MM, et al. Medication use during pregnancy, with particular focus on prescription drugs: 1976-2008. Am J Obstet Gynecol 2011;205:51.e1-8.

8. Lupattelli $A$, Spigset $O$, Twigg MJ, et al. Medication use in pregnancy: a cross-sectional, multinational web-based study. BMJ Open 2014;4:e004365.

9. Engeland A, Bramness JG, Daltveit AK, et al. Prescription drug use among fathers and mothers before and during pregnancy. A population-based cohort study of 106,000 pregnancies in Norway 2004-2006. Br J Clin Pharmacol 2008;65:653-60.

10. Mazurek JM, England LJ. Cigarette smoking among working women of reproductive age-United States, 2009-2013. Nicotine Tob Res 2016;18:894-9.

11. Witt WP, Mandell KC, Wisk LE, et al. Predictors of alcohol and tobacco use prior to and during pregnancy in the US: the role of maternal stressors. Arch Womens Ment Health 2015;18:523-37.

12. Narkowicz S, Płotka J, Polkowska Ż, et al. Prenatal exposure to substance of abuse: a worldwide problem. Environ Int 2013;54:141-63.

13. Sundhedsdatastyrelsen. Sundhedsregistre - Fødsler og fødte avanceret. 2015 http://www.esundhed.dk/sundhedsregistre/MFR/ Sider/MFR06A.aspx (acessed Apr 2017).

14. Doherty SP, Grabowski J, Hoffman C, et al. Early life insult from cigarette smoke may be predictive of chronic diseases later in life. Biomarkers 2009;14(Suppl 1):97-101.

15. Jauniaux E, Burton GJ. Morphological and biological effects of maternal exposure to tobacco smoke on the feto-placental unit. Early Hum Dev 2007;83:699-706.

16. Morris CV, DiNieri JA, Szutorisz H, et al. Molecular mechanisms of maternal cannabis and cigarette use on human neurodevelopment. Eur J Neurosci 2011;34:1574-83.

17. Langley K, Rice F, van den Bree MB, et al. Maternal smoking during pregnancy as an environmental risk factor for attention deficit hyperactivity disorder behaviour. A review. Minerva Pediatr 2005;57:359-71.

18. Behnke M, Smith VC. Committee on Substance AbuseCommittee on Fetus and Newborn. Prenatal substance abuse: short- and long-term effects on the exposed fetus. Pediatrics 2013;131:e1009-24.

19. EMCDDA. Denmark - Country Overview - a summary of the national drug situation. $2013 \mathrm{http}: / /$ www.emcdda.europa.eu/countries/ denmark (accessed Feb 2017).

20. Haervig KB, Mortensen LH, Hansen AV, et al. Use of ADHD medication during pregnancy from 1999 to 2010: a Danish registerbased study. Pharmacoepidemiol Drug Saf 2014;23:526-33.

21. Bro SP, Kjaersgaard MI, Parner ET, et al. Adverse pregnancy outcomes after exposure to methylphenidate or atomoxetine during pregnancy. Clin Epidemiol 2015;7:139-47.

22. Tørring N, Ball $\mathrm{S}$, Wright $\mathrm{D}$, et al. First trimester screening for trisomy 21 in gestational week $8-10$ by ADAM12-S as a maternal serum marker. Reprod Biol Endocrinol 2010;8:129.

23. Telving R, Hasselstrøm JB, Andreasen MF. Targeted toxicological screening for acidic, neutral and basic substances in postmortem and antemortem whole blood using simple protein precipitation and UPLC-HR-TOF-MS. Forensic Sci Int 2016;266:453-61.

24. Ekelund CK, Petersen OB, Jørgensen FS, et al. The Danish Fetal Medicine Database: establishment, organization and quality assessment of the first trimester screening program for trisomy 21 in Denmark 2008-2012. Acta Obstet Gynecol Scand 2015;94:577-83.

25. Henderson AJ, Shaheen SO. Acetaminophen and asthma. Paediatr Respir Rev 2013;14:9-16.

26. Snijder CA, Kortenkamp A, Steegers EA, et al. Intrauterine exposure to mild analgesics during pregnancy and the occurrence of cryptorchidism and hypospadia in the offspring: the Generation $\mathrm{B}$ Study. Hum Reprod 2012;27:1191-201.

27. Jensen MS, Rebordosa C, Thulstrup AM, et al. Maternal use of acetaminophen, ibuprofen, and acetylsalicylic acid during pregnancy and risk of cryptorchidism. Epidemiology 2010;21:779-85. 
28. Hoover RM, Hayes VA, Erramouspe J. Association Between Prenatal Acetaminophen Exposure and Future Risk of Attention Deficit/Hyperactivity Disorder in Children. Ann Pharmacother 2015:49:1357-61.

29. Liew Z, Ritz B, Virk J, et al. Maternal use of acetaminophen during pregnancy and risk of autism spectrum disorders in childhood: $A$ Danish national birth cohort study. Autism Res 2016;9:951-8.

30. Rebordosa C, Kogevinas M, Horváth-Puhó E, et al. Acetaminophen use during pregnancy: effects on risk for congenital abnormalities. Am J Obstet Gynecol 2008;198:178.e1-7.

31. Li DK, Liu L, Odouli R. Exposure to non-steroidal anti-inflammatory drugs during pregnancy and risk of miscarriage: population based cohort study. BMJ 2003;327:368.

32. Nakhai-Pour HR, Broy P, Sheehy O, et al. Use of nonaspirin nonsteroidal anti-inflammatory drugs during pregnancy and the risk of spontaneous abortion. CMAJ 2011;183:1713-20.

33. Ofori $B$, Oraichi $D$, Blais $L$, et al. Risk of congenital anomalies in pregnant users of non-steroidal anti-inflammatory drugs: a nested case-control study. Birth Defects Res B Dev Reprod Toxicol 2006;77:268-79.

34. Etwel F, Faught LH, Rieder MJ, et al. The risk of adverse pregnancy outcome after first trimester exposure to h1 antihistamines: a systematic review and meta-analysis. Drug Saf 2017;40:121-32.

35. Daw JR, Mintzes B, Law MR, et al. Prescription drug use in pregnancy: a retrospective, population-based study in British Columbia, Canada (2001-2006). Clin Ther 2012;34:239-49.

36. Andrade SE, Raebel MA, Brown J, et al. Use of antidepressant medications during pregnancy: a multisite study. Am J Obstet Gynecol 2008;198:194.e1-5.

37. El Marroun H, White T, Verhulst FC, et al. Maternal use of antidepressant or anxiolytic medication during pregnancy and childhood neurodevelopmental outcomes: a systematic review. Eur Child Adolesc Psychiatry 2014;23:973-92.

38. Kjaersgaard MI, Parner ET, Vestergaard M, et al. Prenatal antidepressant exposure and risk of spontaneous abortion - a population-based study. PLoS One 2013;8:e72095.

39. Lorenzo L, Einarson A. Antidepressant use in pregnancy: an evaluation of adverse outcomes excluding malformation. Is $\mathrm{J}$ Psychiatry Relat Sci 2014;51:94-104.

40. Chambers CD, Johnson KA, Dick LM, et al. Birth Outcomes in Pregnant Women Taking Fluoxetine. N Engl J Med Overseas Ed 1996;335:1010-5.

41. Diav-Citrin O, Shechtman S, Weinbaum D, et al. Paroxetine and fluoxetine in pregnancy: a prospective, multicentre, controlled, observational study. Br J Clin Pharmacol 2008;66:695-705

42. Bérard A, Ramos E, Rey E, et al. First trimester exposure to paroxetine and risk of cardiac malformations in infants: the importance of dosage. Birth Defects Res B Dev Reprod Toxicol 2007;80:18-27.

43. Källén BA, Otterblad Olausson P. Maternal use of selective serotonin re-uptake inhibitors in early pregnancy and infant congenital malformations. Birth Defects Res A Clin Mol Teratol 2007;79:301-8.

44. Coughlin CG, Blackwell KA, Bartley C, et al. Obstetric and neonatal outcomes after antipsychotic medication exposure in pregnancy. Obstet Gynecol 2015;125:1224-35.

45. Terrana N, Koren G, Pivovarov J, et al. Pregnancy Outcomes Following In Utero Exposure to Second-Generation Antipsychotics:
A Systematic Review and Meta-Analysis. J Clin Psychopharmacol 2015;35:559-65.

46. Kulaga S, Sheehy O, Zargarzadeh $\mathrm{AH}$, et al. Antiepileptic drug use during pregnancy: perinatal outcomes. Seizure 2011:20:667-72.

47. Bakker MK, Jentink J, Vroom F, et al. Drug prescription patterns before, during and after pregnancy for chronic, occasional and pregnancy-related drugs in the Netherlands. BJOG 2006;113:559-68.

48. Kesmodel U, Kesmodel PS, Larsen A, et al. Use of alcohol and illicit drugs among pregnant Danish women, 1998. Scand J Public Health 2003;31:5-11.

49. Bech BH, Nohr EA, Vaeth M, et al. Coffee and fetal death: a cohort study with prospective data. Am J Epidemiol 2005;162:983-90.

50. Liu X, Liew Z, Olsen J, et al. Association of prenatal exposure to acetaminophen and coffee with childhood asthma. Pharmacoepidemiol Drug Saf 2016;25:188-95.

51. Goldstein A, Warren R. Passage of caffeine into human gonadal and fetal tissue. Biochem Pharmacol 1962;11:166-8.

52. Li J, Zhao H, Song JM, et al. A meta-analysis of risk of pregnancy loss and caffeine and coffee consumption during pregnancy. Int $J$ Gynaecol Obstet 2015;130:116-22.

53. Hinds TS, West WL, Knight EM, et al. The Effect of Caffeine on Pregnancy Outcome Variables. Nutr Rev 1996;54:203-7.

54. Bakker R, Steegers EA, Obradov A, et al. Maternal caffeine intake from coffee and tea, fetal growth, and the risks of adverse birth outcomes: the Generation R Study. Am J Clin Nutr 2010;91:1691-8.

55. Eskenazi B, Stapleton AL, Kharrazi M, et al. Associations between maternal decaffeinated and caffeinated coffee consumption and fetal growth and gestational duration. Epidemiology 1999;10:242-9.

56. Thomopoulos TP, Ntouvelis E, Diamantaras AA, et al. Maternal and childhood consumption of coffee, tea and cola beverages in association with childhood leukemia: a meta-analysis. Cancer Epidemiol 2015;39:1047-59.

57. Yuede CM, Olney JW, Creeley CE. Developmental neurotoxicity of alcohol and anesthetic drugs is augmented by co-exposure to caffeine. Brain Sci 2013;3:1128-52.

58. Cabrera $\mathrm{OH}, \mathrm{O}^{\prime}$ Connor SD, Swiney BS, et al. Caffeine combined with sedative/anesthetic drugs triggers widespread neuroapoptosis in a mouse model of prematurity. J Matern Fetal Neonatal Med 2016:1-8.

59. Petersen I, McCrea RL, Lupattelli A, et al. Women's perception of risks of adverse fetal pregnancy outcomes: a large-scale multinational survey. BMJ Open 2015;5:e007390.

60. Andres RL, Day M-C. Perinatal complications associated with maternal tobacco use. Seminars in Neonatology 2000;5:231-41.

61. Backhausen MG, Ekstrand M, Tydén T, et al. Pregnancy planning and lifestyle prior to conception and during early pregnancy among Danish women. Eur J Contracept Reprod Health Care 2014;19:57-65.

62. Landau LI. Tobacco smoke exposure and tracking of lung function into adult life. Paediatr Respir Rev 2008;9:39-44.

63. Oken E, Huh SY, Taveras EM, et al. Associations of maternal prenatal smoking with child adiposity and blood pressure. Obes Res 2005;13:2021-8.

64. Mamsen LS, Lutterodt MC, Andersen EW, et al. Cigarette smoking during early pregnancy reduces the number of embryonic germ and somatic cells. Hum Reprod 2010;25:2755-61. 